\title{
Possible Teratogenic Potential of Human Chorionic Gonadotropin Treatment - A Population-Based Case-Control Study
}

\author{
István Dudás ${ }^{1}$, Andrew E. Czeizel ${ }^{* 1}$ and Ferenc Bánhidy ${ }^{2}$ \\ ${ }^{I}$ Foundation for the Community Control of Hereditary Diseases, Budapest, Hungary; ${ }^{2}$ Second Department of Obstetrics \\ and Gynecology, Semmelweis University, School of Medicine, Budapest, Hungary
}

\begin{abstract}
Human chorionic gonadotropin (hCG) is used for treatment of pregnant women with threatened and repeated miscarriages/spontaneous abortions in Hungary. Thus the objective of the study was to evaluate the possible association of medically recorded hCG treatment during the second and/or third gestational month in pregnant women with the risk of different congenital abnormalities in their offspring on the basis of comparison to pregnant women who were also treated with hCG and delivered control newborns without any defect in the population-based Hungarian Case-Control Surveillance of Congenital Abnormalities, 1980-1996. Of 22,843 cases with congenital abnormalities, 83 (0.36\%), while of 38,151 controls without any defect, $97(0.25 \%)$ had mothers with hCG treatment (adjusted OR with 95\% CI: 1.6, 1.22.1 ), though there was no association between any congenital abnormality group and a higher rate of maternal hCG treatment. In conclusion the detectable slight general risk for congenital abnormalities in the offspring of mothers with hCG treatment during early pregnancy may be connected with other factors, particularly the causes of previous miscarriages.
\end{abstract}

Keywords: Human chorionic gonadotropin, pregnancy, congenital abnormalities, case-control study.

\section{INTRODUCTION}

Human chorionic gonadotropin (hCG) is a natural placental hormone produced by the syncytiotrophoblast and extracted from the urine of pregnant women with a light luteal hormone activity and with a half-life of 29-30 hours [1]. In most countries hCG is primarily used as ovarian stimulants in the protocol of assisted reproductive methods, especially in vitro fertilization (IVF) [2]. However, hCG is used parenterally for the treatment of female infertility due to anovulation and luteal phase deficiency or of threatened and repeated miscarriages (spontaneous abortion or early fetal death) in pregnant women in Hungary. Our previous study did not confirm the expected protective effect of hCG treatment for miscarriages in pregnant women with threatened abortion/miscarriage [3]. These findings were agreement with the conclusion of recent Cochrane review that the current evidence does not support the routine use of hCG in the treatment of threatened abortion [4]. Thus after the disproval of supposed benefit of hCG treatment in pregnant women with threatened abortion, the objective of our recent study was to evaluate the possible association of teratogenic risk of hCG treatment during the second and/or third month of pregnant women with the risk of different structural birth defects, i.e. congenital abnormalities (CAs) in their offspring in the population-based large data set of the Hungarian Case-Control Surveillance of Congenital Abnormalities (HCCSCA) [5].

*Address correspondence to this author at the 1026 Törökvész lejtő 32, Budapest, Hungary; Tel: 36-1-3944-712; Fax: 36-1-3944-712;

E-mail: czeizel@interware.hu

\section{MATERIALS AND METHODOLOGY}

The HCCSCA is based on the comparison of exposures in the mothers of cases with CAs and in the mothers of controls without any CA.

Cases affected with CA are selected from the Hungarian Congenital Abnormality Registry (HCAR) for the HCCSCA [6]. The reports of cases with CAs is mandatory for physicians, and most are reported by obstetricians (in Hungary practically all deliveries take place in inpatient obstetric clinics and birth attendants are obstetricians) and paediatricians (who are working in the neonatal units of inpatient obstetric clinics and various general and specialised such as surgical, cardiologic, orthopaedic, etc. inpatient and outpatient paediatric clinics). Autopsy was obligatory for all infant deaths and common $(80 \%)$ in stillborn fetuses during the study period. Pathologists sent a copy of the autopsy report to the HCAR if defects were identified in stillbirths and infant deaths. Data from prenatal diagnostic centres have also been included in the HCAR since 1984 after the diagnosis of fetal defect with or without termination of pregnancy. Isolated minor anomalies/morphological variants (e.g., umbilical hernia) were recorded but not evaluated in the HCAR. The total (birth + fetal) prevalence of cases with CA diagnosed from the second trimester of pregnancy through the age of one year was 35 per 1000 informative offspring (liveborn infants, stillborn fetuses and electively terminated malformed fetuses after their prenatal diagnosis) in the HCAR, 1980-1996 [6] and about $90 \%$ of major CAs were reported to the HCAR during the 17 years of the study period [7].

There were three exclusion criteria of the case selection for the HCCSCA from the HCAR: cases (i) reported after 
three months of birth (23\% of cases), (ii) with three mild CAs such as congenital dysplasia of hip and inguinal hernia, large haemangioma and (iii) with CA-syndromes caused by major mutant genes and chromosomal aberrations with preconceptional origin were excluded. CAs were differentiated according to their total prevalence, severity and the validity of diagnosis into 25 groups including 24 isolated CAs and one multiple CA group in the HCCSCA.

Controls were defined as newborns without CA and in general two controls (but three controls between 1986 and 1992) were selected from the National Birth Registry of the Central Statistical Office for the HCCSCA for each case and they were matched to cases according to sex, birth week in the year when the case was born and district of mothers' residence. These controls were selected on the basis of case list forwarded by the co-workers of the HCAR in each quarter of the year to the administrators of the National Birth Registry, and after the selection of controls they provided them with name and address for the co-workers of the HCAR.

\section{EXPOSURE DATA WERE OBTAINED FROM THREE SOURCES}

(1) Prospective medically recorded data: mothers were asked in an explanatory letter to send us the prenatal maternity logbook and other medical records (mainly discharge summaries) concerning their diseases during the study pregnancy and their child's CA. Prenatal care was mandatory for pregnant women in Hungary (if somebody did not visit prenatal care, she did not get maternity grant and leave), thus nearly $100 \%$ of pregnant women visited prenatal care with a first visit in the 6-12 weeks of gestation and with an average of 7 visits during the study pregnancy. The task of obstetricians in the prenatal care is to record all pregnancy complications, maternal diseases and drug treatments in the prenatal maternity logbook.

(2) Retrospective self-reported maternal information: a structured questionnaire along with a list of medicines and diseases, in addition an informed consent were also mailed to the mothers immediately after the selection of cases and controls. The questionnaire requested information on medicinal product (drug and pregnancy supplement) intakes, pregnancy complications and maternal diseases during pregnancy according to gestational months and the family history of CA. To standardize the answers, mothers were asked to read the enclosed lists of drugs and diseases as memory aid before they replied.

The mean $( \pm$ S.D) time elapsed between the end of pregnancy and return of the information package including logbook, questionnaire and signed informed consent in a prepaid envelop was $3.5 \pm 1.2$ and $5.2 \pm 2.9$ months in the case and control groups, respectively.

(3) Supplementary data collection: regional nurses were asked to visit all non-respondent case mothers and they helped mothers to fill-in the same questionnaire and evaluated the available medical data to obtain the necessary exposure data, in addition they asked a signature for informed consent. Regional nurses did not visit all nonrespondent control mothers because committee on ethics considered this follow-up to be disturbing to the parents of healthy children. Thus only 200 non-respondent and 600 respondent control mothers selected randomly were visited and evaluated in two validation studies $[8,9]$. The frequency of medicinal product intakes including folic acid did not show significant differences between respondent and non-respondent women [5,8].

A flowchart of cases and controls in the HCCSCA has been published previously [10]. The preliminary case group included 75,830 cases, but 4,977 $(6.6 \%)$ had undelivered letters due to new or unknown addresses, however, regional nurses did their best to find and to visit them at home as in 2,084 non-respondent mothers. Of 89,351 selected controls, $33,702(30.8 \%)$ had undelivered letters due their unknown addresses. Thus addresses of case mothers in the HCAR had a much higher accuracy than the addresses of control mothers in the National Birth Registry. In addition all nonrespondent case mothers and case mothers with previously undelivered letters, but recently identified addresses by regional nurses were visited at home while this number was only 200 in the group of control mothers. These differences explains that the number of controls per cases is $1: 1.7$ instead of $1: 2.4$.

Overall, necessary information was available on $96.3 \%$ of cases (84.4\% from reply, $11.9 \%$ from visit) and $83.0 \%$ of the controls (82.6\% from reply, $0.4 \%$ from visit) after the exclusion of cases and controls with undelivered letters, i.e. unknown addresses. The informed consent document was signed by $98.4 \%$ of mothers; the name and address in the rest of subjects were deleted in the HCCSCA.

In Hungary three kinds of hCG: (i) Choriogonin ${ }^{\circledR}$, Richter, and (ii) Choragon ${ }^{\circledR}$, Ferring, 1500 or 5000 IU, (iii) Profasi ${ }^{\circledR}$, Serono, 2000 or 5000 IU per ampoule were available for parenteral treatment. First the hCG treatment was evaluated according to the source of information: prospective medically recorded, retrospective maternal information and both. However, the preliminary evaluation of these exposure data showed that maternal information was unreliable due to this parenteral hCG treatment because several mothers mentioned only "injection treatment" without the specification of drug. hCG use was reported only by 3 case and 2 control mothers without recording these treatments in prenatal maternity logbook, these pregnant women were excluded from the study. Thus finally only prospective medically recorded hCG treatments in the prenatal maternity logbooks and/or in discharge summaries of hospitalized pregnant women were evaluated. The doses of hCG, in addition the onset and duration of this treatment according to gestational time were also evaluated.

Gestational time was calculated from the first day of the last menstrual period and three time intervals were considered: (i) First month of pregnancy, it is before the organogenesis. The first two weeks are before conception, while the third and fourth weeks comprise the pre- and implantation period of zygotes and blastocysts consisting of stem cells with "all-or-nothing effect" rule, i.e. CA cannot be induced by environmental agents. (ii) The second and third month of gestation as the most sensitive, that is the so-called critical period for most major CAs. (iii) The fourth-ninth months of gestation. 
Among potential confounding factors, maternal age, birth and pregnancy order, maternal employment as indicator of socioeconomic status [11] were evaluated only on the basis of maternal information in the questionnaire. Acute and chronic maternal disorders, the use of other drugs and folic acid supplement [12] were also mentioned in the maternal questionnaire. The incidence of pregnancy complications and acute maternal diseases, in addition the prevalence of chronic diseases and their related drug treatments were recorded in the prenatal maternity logbook as well. Thus the latter data were evaluated from both sources.

The statistical analysis was performed using the software package SAS version 8.02 (SAS Institute Inc., Cary, North Caroline, USA). First contingency tables were prepared for the main study variables and OR for hCG treatment in the models with and without inclusion of potential confounders were evaluated. If maternal variables showed significant associations with hCG treatment, they were included to the spectrum of confounders. Among potential confounding factors, continuous variables were analyzed using Student's $t$ test, while the chi-square test was calculated for the categorical variables. There was 0.05 or lower statistical power accepted for the detection of differences. At the analysis of pregnancy complications, acute and chronic maternal diseases crude odds ratio (OR) with $95 \%$ confidence interval ( $95 \%$ CI) was used for the comparison of study groups. The frequency of hCG treatment in mothers of cases with different CA groups and in the mothers of all matched controls was compared and adjusted OR with $95 \%$ CI was evaluated in conditional logistic regression models. However, hCG treatment was differentiated according to gestational time and by indication as well. The OR were adjusted for maternal age $(<24 \mathrm{yr} v s .25-29 \mathrm{yr} v s .30 \mathrm{yr}$ or more), birth order (first delivery $v s$. one or more previous deliveries), pregnancy order (first pregnancy outcomes $v s$. one or more previous pregnancy outcomes), maternal employment status (professional-managerial-skilled worker vs. semiskilled worker-unskilled worker-housewife vs. others), other frequently used drugs for the prevention/treatment of threatened abortion (yes/no) and folic acid/multivitamin supplementation in the first trimester (as a dichotomous variable).

\section{RESULTS}

Of 22,865 informative offspring (malformed fetuses and newborns), $113(0.49 \%)$ had mothers with medically recorded hCG treatment during pregnancy. The total number of births was 2,146,574 in Hungary during the study period; hence 38,151 controls represented $1.8 \%$ of all Hungarian births. Of these 38,151 controls without any CA, 137 $(0.36 \%)$ had mothers with medically recorded hCG treatment during pregnancy (crude OR with 95\% CI: 1.4, 1.1-1.8).

However, hCG treatment occurred only in the first gestational month due to infertility in 29 case mothers and 37 control mothers, and it was not continued in the second gestational month after the recognition of pregnancy. Of these 29 cases, 2, while of 37 controls, 1 had mother with conception due to IVF. In Hungary the first IVF occurred in 1989, and IVF was used more frequently after 1996. The onset of hCG treatment was after the third gestational month in 1 case mother and 3 control mothers. Pregnant women with hCG treatment before the second and after the third gestational months were excluded from the study.

Thus finally 83 case and 97 control mothers with hCG treatment during the second $(61.4 \%$ vs. $61.9 \%)$ and/or third (38.6\% vs. $38.1 \%)$ gestational months were evaluated in the study, the proportion of hCG treatment's onset is shown in brackets.

Table 1 summarizes the maternal characteristics in case and control mothers with hCG treatment during the second and/or third month of gestation and without hCG treatment as reference. Mean maternal age was higher in treated mothers than in untreated pregnant women due to the higher proportion of women over 25 years. Nevertheless, the mean birth order was lower in hCG treated women than in untreated pregnant females. This discrepancy can be explained by the higher mean pregnancy order (i.e. previous births and miscarriages) because the difference between mean birth order and pregnancy order was 0.2 in untreated pregnant women but 0.9 in hCG treated case mothers and 0.7 in hCG treated control mothers. We can calculate this difference in percentage figures on the basis of absolute number of first pregnancy and birth order, thus the rate of previous miscarriage was $4.0 \%$ and $4.8 \%$ in hCG untreated case and control pregnant women, while $31.3 \%$ and $33.0 \%$ in hCG treated case and control mothers, respectively. The higher proportion of pregnant women with previous miscarriage therefore resulted in a lower mean birth order in pregnant women with hCG treatment. The proportion of professional and managerial women was larger, while the proportion of semi- and unskilled workers, in addition housewives (most women in this category belong to low socio-economic status) were smaller in hCG treated women. However, there was no difference in these variables between treated case and control mothers.

In general, the use of pregnancy supplements was similar between case and control mothers treated with hCG. The exception was folic acid, of 83 case mothers, $44(53.0 \%)$ were supplemented with folic acid during pregnancy, while of 97 control pregnant women, $69(71.1 \%)$ used folic acid (OR with 95\% CI: $0.5,0.2-0.8$ ).

The incidence of medically recorded pregnancy complications in the prenatal maternity logbooks is shown in Table 2. Here only control mothers are mentioned because CAs in the offspring of case mothers may modify the incidence of pregnancy complications. There was a much higher rate of threatened abortion in pregnant women with hCG treatment as the main indication of hCG. However, the rate of threatened preterm delivery was also higher in treated pregnant women, but of these 28 pregnant women, 14 had also threatened abortion as well. The rate of placental disorders was also higher in treated pregnant women, however, of these 5 pregnant women, all had threatened preterm delivery and among them one was recorded with threatened abortion as well. The higher incidence of gestational diabetes was based on only 3 pregnant women in the hCG treated group.

In the next step the indication of hCG treatments was evaluated. Thus, of 83 case mothers with hCG treatment, 71 $(85.5 \%)$ had threatened abortion with or without miscarriages in their previous pregnancies. In addition, 12 case mothers without threatened abortion were treated with hCG 
Table 1. Characteristics of Case and Control Mothers with or without Human Chorionic Gonadotropin (hCG) Treatment During the Second and/or Third Month of Gestation

\begin{tabular}{|c|c|c|c|c|c|c|c|c|c|}
\hline \multirow{3}{*}{$\begin{array}{l}\text { Maternal } \\
\text { Variables }\end{array}$} & \multicolumn{4}{|c|}{ Case Mothers } & \multicolumn{4}{|c|}{ Control Mothers } & \multirow{3}{*}{$\begin{array}{l}\text { Comparison between Treated Case and Control Moth- } \\
\text { ers }\end{array}$} \\
\hline & \multicolumn{2}{|c|}{$\begin{array}{l}\text { Untreated } \\
(\mathrm{N}=\mathbf{2 2 , 7 6 0 )}\end{array}$} & \multicolumn{2}{|c|}{$\begin{array}{l}\text { Treated } \\
(\mathbf{N}=83)\end{array}$} & \multicolumn{2}{|c|}{$\begin{array}{l}\text { Untreated } \\
(\mathrm{N}=\mathbf{3 8 , 0 5 4})\end{array}$} & \multicolumn{2}{|c|}{$\begin{array}{l}\text { Treated } \\
(\mathbf{N}=97)\end{array}$} & \\
\hline & No. & $\%$ & No. & $\%$ & No. & $\%$ & No. & $\%$ & \\
\hline \multicolumn{10}{|l|}{ Quantitative } \\
\hline \multicolumn{10}{|l|}{ Maternal age (yr) } \\
\hline 24 or less & 10,293 & 45.2 & 22 & 26.5 & 17,961 & 47.2 & 33 & 34.0 & \\
\hline $25-29$ & 7,750 & 34.1 & 34 & 41.0 & 12,846 & 33.8 & 39 & 40.2 & \multirow{2}{*}{$\mathrm{X}_{2}^{2}=1.5 \mathrm{p}=0.46$} \\
\hline 30 or more & 4,717 & 20.7 & 27 & 32.5 & 7,247 & 19.0 & 25 & 25.8 & \\
\hline Mean \pm S.D. & \multicolumn{2}{|c|}{$25.4 \pm 5.3$} & \multicolumn{2}{|c|}{$27.4 \pm 4.7$} & \multicolumn{2}{|c|}{$25.4 \pm 4.9$} & \multicolumn{2}{|c|}{$26.8 \pm 4.6$} & $\mathrm{t}=0.9 \quad \mathrm{p}=0.36$ \\
\hline \multicolumn{10}{|l|}{ Birth order } \\
\hline 1 & 10,650 & 46.8 & 58 & 69.9 & 18,141 & 47.7 & 68 & 70.1 & \multirow{2}{*}{$\mathrm{X}^{2}{ }_{1}=0.0 \quad \mathrm{p}=0.97$} \\
\hline 2 or more & 12,110 & 53.2 & 25 & 30.1 & 19,913 & 52.3 & 29 & 29.9 & \\
\hline Mean \pm S.D. & \multicolumn{2}{|c|}{$1.9 \pm 1.1$} & \multicolumn{2}{|c|}{$1.4 \pm 0.8$} & \multicolumn{2}{|c|}{$1.8 \pm 0.9$} & \multicolumn{2}{|c|}{$1.4 \pm 0.6$} & $\mathrm{t}=0.9 \mathrm{p}=0.90$ \\
\hline \multicolumn{10}{|l|}{ Pregnancy order } \\
\hline 1 & 9,741 & 42.8 & 32 & 38.6 & 16,325 & 42.9 & 36 & 37.1 & \multirow[t]{2}{*}{$\mathrm{X}^{2}{ }_{1}=0.04 \mathrm{p}=0.84$} \\
\hline 2 or more & 13,019 & 57.2 & 51 & 61.4 & 21,729 & 57.1 & 61 & 62.9 & \\
\hline Mean \pm S.D. & \multicolumn{2}{|c|}{$2.1 \pm 1.4$} & \multicolumn{2}{|c|}{$2.3 \pm 1.6$} & \multicolumn{2}{|c|}{$2.0 \pm 1.2$} & \multicolumn{2}{|c|}{$2.1 \pm 1.2$} & $\mathrm{t}=1.0 \mathrm{p}=0.96$ \\
\hline Categorical & & & & & & & & & \\
\hline Unmarried & 1,265 & 5.6 & 4 & 4.8 & 1,470 & 3.9 & 1 & 1.0 & \\
\hline Employment status & & & & & & & & & \\
\hline Professional & 1,881 & 8.3 & 20 & 24.1 & 4,330 & 11.4 & 23 & 23.7 & \\
\hline Managerial & 4,945 & 21.7 & 23 & 27.7 & 10,104 & 26.6 & 30 & 30.9 & \\
\hline $\begin{array}{l}\text { Skilled } \\
\text { worker }\end{array}$ & 6,308 & 27.7 & 21 & 25.3 & 11,660 & 30.6 & 30 & 30.9 & $\mathrm{X}_{6}^{2}=4.0 \mathrm{p}=0.68$ \\
\hline $\begin{array}{l}\text { Semiskilled } \\
\text { worker }\end{array}$ & 3,857 & 17.0 & 12 & 14.5 & 5,774 & 15.2 & 9 & 9.3 & \\
\hline $\begin{array}{l}\text { Unskilled } \\
\text { worker }\end{array}$ & 1,502 & 6.6 & 1 & 1.2 & 1,859 & 4.9 & 0 & 0.0 & \\
\hline Housewife & 2,124 & 9.3 & 4 & 4.8 & 2,036 & 5.4 & 2 & 2.1 & \\
\hline Others & 2,143 & 9.4 & 2 & 2.4 & 2,291 & 6.0 & 3 & 3.1 & \\
\hline
\end{tabular}

because all of them had miscarriages in their previous pregnancies. Of 97 control mothers. 77 (79.4\%) had threatened abortion with or without miscarriages in their previous pregnancies and 20 were recorded with miscarriages in their previous pregnancies without the symptoms of threatened abortion in the study pregnancy. In general first $10,000 \mathrm{IU}$ of hCG were given followed by twice 5000 IU per week until the 14th

There was no difference in the incidence of acute maternal disorders such as influenza and common cold with secondary complications, diseases of respiratory, digestive, urinary systems and genital organs between the study groups.
All kinds of recorded chronic maternal diseases were evaluated, but the prevalence of diabetes mellitus, epilepsy and others did not show significant differences among the study groups.

Drugs used for threatened abortion such as allylestrenol (33.7\% vs. 33.0\%), promethazine $(30.1 \%$ vs. 30.9\%), drotaverine (19.2\% vs. $21.6 \%$ ), diazepam (16.9\% vs. $15.5 \%)$ had a much higher frequency in hCG treated case and control mothers (see figures in brackets) than in untreated pregnant women. However, there was no difference in the frequency of these drugs between hCG treated case and control mothers. Other drugs did not show significant differences among 
Table 2. Incidence of Medically Recorded Pregnancy Complications in the Groups of Case and Control Pregnant Women with or without hCG Treatment

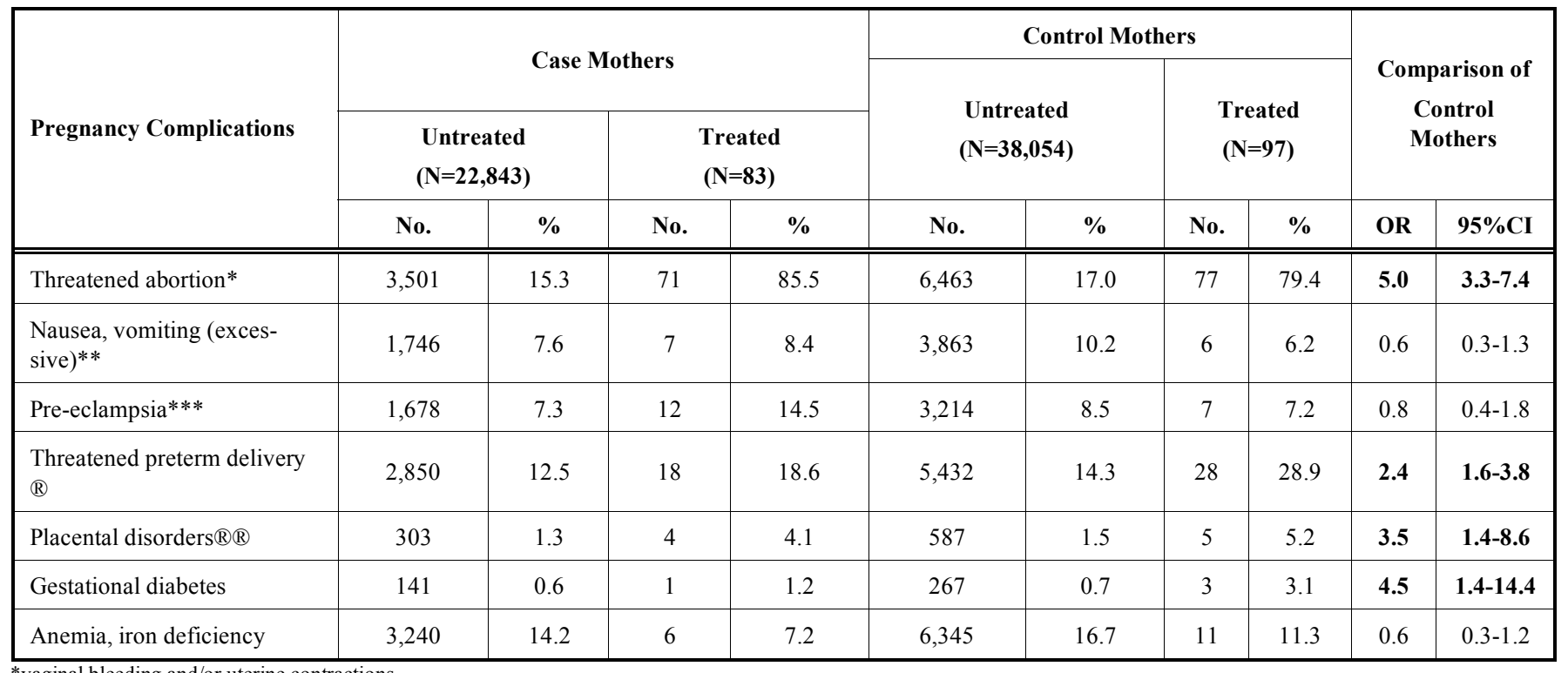

*vaginal bleeding and/or uterine contractions.

** prospectively and medically recorded, in addition treated with antiemetic drugs.

$* * *$ including pregnancy hypertension, oedema and albuminuria.

(Rincluding cervical incompetence as well.

$(\mathbb{R}$ including placenta previa, premature separation of placenta, anterpartum hemorrhage.

the study groups. There were no pregnant women with threatened abortion who were treated only with hCG treatment, all of them had other drug treatments as well.

Table 3 shows the major findings of the study, i.e. the comparison of the frequency of hCG treatment during the second and/or third gestational month in pregnant women who had cases with different CA-groups (including at least 3 cases) and in pregnant women who delivered controls without any CA and matched to cases. There was no CA group in cases with higher hCG treatment in their mothers (i.e. the lower confidence interval of OR did not exceed 1). However, the adjusted OR for hCG treatment in the total CA group was $1.6,1.2-2.1$.

In the next step the total (birth + electively terminated malformed fetuses after prenatal diagnoses) prevalence of different CAs were compared only in pregnant women with threatened abortion in two groups: (i) $71 \mathrm{hCG}$ treated pregnant women with other treatments and (ii) 3,501 pregnant women without hCG treatment but other treatments. (All pregnant women with threatened abortion were treated, thus a third subgroup without any treatment was not available.) The mean maternal age and birth order of 3,501 case mothers with threatened abortion but without hCG treatment was $25.7 \pm 4.8$ and $1.7 \pm 0.9$, respectively. Threatened abortion of these pregnant women associated with a higher risk of threatened preterm delivery $(22.2 \% \mathrm{vs} .12 .7 \%)$ and placental disorders $(3.0 \%$ vs. $1.2 \%)$ compared to pregnant women without threatened abortion and hCG treatment. Among maternal diseases, only essential hypertension occurred more frequently in pregnant women with threatened abortion $(9.2 \%$ vs. 6.6\%). The total rate of CAs was not higher in the offspring of pregnant women with threatened abortion but without hCG treatment (OR with 95\% CI: 0.86, 0.77-0.94) compared to the reference control group and only one $\mathrm{CA}$ group: anal/rectal atresia/stenosis showed a marginally higher risk (OR with 95\% CI: 1.3, 1.0-1.8). Thus the somewhat higher risk of total CAs in the offspring of 83 pregnant women with hCG treatment cannot be explained by threatened abortion.

\section{DISCUSSION}

We examined the teratogenic risk of parenteral $\mathrm{hCG}$ treatments during the second and/or third month of pregnancy and our analysis did not show a higher risk for any CA group. However, the population-based data set of the HCCSCA showed a slightly higher risk for the total group of CAs after parenteral hCG treatment during the second and/or third gestational month.

The data of four animal investigations have been published regarding CAs in the offspring of pregnant animals treated with hCG before conception. Sakai and Endo [13] showed an increase in the occurrence of open eyelids and cleft palate in the offspring of pregnant mice after the intraperitoneal treatment of 2, 5, 5.0 or $10.0 \mathrm{IU}$ of hCG. A higher rate of deformation in the skeleton (curved vertebral column, club foot, and flexed wrist joints) and a few cleft palate were found in the offspring of pregnant mice after the preconceptional treatment of 100 IU of hCG by Nishimura and Shikata [14]. However, this higher risk may be the secondary consequences of increased litter number, which can result in some deformation of vertebral column and extremities. Our study was not able to confirm these findings after the hCG treatment of pregnant women during the critical period of major CAs. On the other hand two investigations in pregnant rat did not show any increase in the rate of CA after hCG treatment $[15,16]$

The results of two human studies have been published. In the epidemiological study of Källen and Olausson [17], of 
Table 3. Matched Analysis of Cases with Congenital Abnormalities (CAs) and Controls without CA to Estimate the Association Between hCG Treatment During the Second and/or Third Month of Pregnancy and the Risk of Different CA

\begin{tabular}{|c|c|c|c|c|c|}
\hline Study Groups & $\frac{\text { Grand Total }}{\mathrm{N}}$ & No. & $\%$ & $\begin{array}{c}\text { Crude } \\
\text { OR }(95 \% \mathrm{CI})\end{array}$ & $\begin{array}{c}\text { Adjusted } \\
\mathrm{OR} *(95 \% \mathrm{CI})\end{array}$ \\
\hline \multicolumn{6}{|l|}{ Isolated CAs } \\
\hline Neural-tube defects & 1,202 & 6 & 0.5 & $2.6(0.7-9.6)$ & $2.7(0.7-9.8)$ \\
\hline Hypospadias & 3,038 & 12 & 0.4 & $1.5(0.7-3.3)$ & $1.7(0.8-3.8)$ \\
\hline Undescended testis & 2,051 & 3 & 0.2 & $0.5(0.1-2.1)$ & $0.5(0.1-2.1)$ \\
\hline $\begin{array}{l}\text { Exompha- } \\
\text { los/Gastroschisis }\end{array}$ & 238 & 3 & 1.3 & $2.0(0.3-12.3)$ & $2.5(0.4-16.0)$ \\
\hline Poly/syndactyly & 1,744 & 5 & 0.3 & $0.8(0.3-2.5)$ & $1.0(0.3-3.2)$ \\
\hline Other isolated CAs & 4,376 & $16^{* *}$ & 0.4 & $1.4(0.6-3.1)$ & $1.5(0.8-3.5)$ \\
\hline Multiple CAs & 1,349 & 8 & 0.6 & $2.6(0.9-7.6)$ & $2.8(0.9-8.2)$ \\
\hline Total cases & 22,843 & 83 & 0.4 & $1.4(1.1-1.9)$ & $1.6(1.2-2.1)$ \\
\hline
\end{tabular}

* matched OR adjusted for maternal age, birth order, employment status, other drug uses and folic acid use during pregnancy in conditional logistic regression model.

**rectal/anal atresia/stenosis in 2 cases, esophageal atresia, renal agenesis, urethral valve stenosis (obstructive CA of urinary tract), primary microcephaly, congenital hydrocephaly, congenital cataract, congenital pyloric stenosis, atresia of bile duct, diaphragmatic CA, absence of vertebra, congenital cystic lung, ankyloglossia, giant kidney, torticollis in 1-1 case. Bold numbers show significant associations.

757 pregnant women with hCG treatment in early pregnancy, 12 had cardiovascular CAs (OR with 95\% CI: 1.8, 1.0-3.1). The prevalence at birth of CAs was $7 \%$ in pregnant women with hCG treatment in the clinical study of Caspi et al. [18], and this rate is high but the authors did not consider it to be elevated. However, both studies were based on women with infertility problems and most had IVF, thus our study groups are not comparable with them.

A steep rise of hCG is a consistent feature in the preimplantation period of normal pregnancy, the average doubling time for hCG is about 38 hours. However, abnormal pregnancies have a deficiency in the production of hCG which is reflected both the low hCG level and a lower rate of its increase [19]. Pregnant women with slow rising of beta-hCG should not be given an optimist prognosis, thus it is reasonable to substitute external hCG treatment in these pregnant women [20]. However, it seems to be unreasonable to suspect any teratogenic effect of this natural placental hormone. This idea may explain that while the teratogenic potential of chlomiphene and bromocriptine was studied frequently [21], teratogenic potential of hCG used during pregnancy was rarely evaluated [22].

We were not able to find an association between any CA group and hCG treatment during the second and/or third gestational month of pregnancy; i.e. during the critical period of most major CAs. Thus our finding is against a possible specific teratogenic effect of hCG because CAs cannot be regarded as a single homogeneous outcome, teratogens tends to increase rates of specific CAs or CA-syndromes [23]. On the other hand the number of cases with specific CAs is too low in our study to draw final conclusion.

The higher total rate of CAs in the offspring of case mothers with hCG treatment was found in our study and it needs some explanation. (i) The infertility of mothers may associate with a higher rate of total CAs [24]. However, infertile women with preconceptional hCG treatment were excluded from our study. Nevertheless, the possible infertility of our case and control women with hCG treatment during pregnancy was indicated by the larger proportion of women over 25 years. (ii) Nearly one-third of our pregnant women had previous miscarriages, and this pregnancy history may contribute to the diagnosis of threatened abortion in the study pregnancy. Pregnant women with previous, particularly repeated miscarriages may have a higher rate of unbalanced chromosomal aberrations, major mutant genes, uterus abnormalities, hormonal dysfunction, maternal diseases such as SLE, etc and these factors may associate with a higher risk for CAs. (iii) There was a somewhat higher risk of CAs (OR with 95\% CI: 1.5, 1.1-2.1) in the newborn infants of pregnant women with threatened abortion/miscarriages in a Chinese study [25]. The possible risk of CAs in informative offspring of pregnant women with threatened abortion was evaluated in the HCCSCA as well but this analysis did not find a higher risk of total CAs [26]. However, only a minor part of these pregnant women $(2.0 \%$ of case mothers and $1.3 \%$ of control mothers) were treated 
with hCG in the dataset of the HCCSCA. (iv). Relaxed selection of fetal defects [27] is another possible explanation because the indication of hCG treatment was threatened abortion in the study. (v) Pregnant women with hCG treatment were treated by other drugs as well due to their threatened abortion. However, allylestrenol [28], promethazine [29, 30], drotaverine [31] and diazepam [32,33] in pregnant women with threatened abortion had no teratogenic potential. (v) A significantly lower rate of folic acid use was found in early pregnancy of case mothers than in control mothers. Folic acid and folic acid-containing multivitamins may reduce the incidence of neural-tube defects and some others CAs [12], therefore this confounder was considered at the calculation of adjusted OR.

Thus the somewhat higher risk of total CAs in the offspring of pregnant women treated with hCG may be associated with other factors, mainly with the causes of previous miscarriages.

The strengths of the HCCSCA are that it is (i) a population-based and (ii) large data set including 180 women (iii) with medically recorded hCG treatment (iv) including data on the timing of treatment during pregnancy; (v) the matching of cases and their controls without CAs; (vi) the knowledge of potential confounders and (vii) the good validity of CA-diagnoses due to the medically reported and checked CAs in the HCAR [6], in addition the results of recent medical examinations were used between the time of report on cases with CA to the HCAR, in general immediately after birth, and the time of sending of "information package", i.e. $3.5 \pm 1.2$ months later to the HCCSCA [5].

However, this dataset also has limitations. (i) The response rate was $82.6 \%$ in controls and $84.4 \%$ in cases but there was an active follow-up for all non-respondent case mothers, while only for 200 non-respondent control mothers. However, there was no significant difference in the frequency of drug use in the subgroups of respondent and nonrespondent pregnant women [8]. Thus, the effect of selection bias seems to be limited in the study. (ii) There was a longer time interval between pregnancy end and return of information package in the control group $(\mathrm{t}=84.4 ; \mathrm{p}<0.001)$. However, recall bias is excluded in medically recorded hCG treatment. (iii) Most women who used hCG were also treated with other drugs, but their proportions were similar in the study groups and previous studies did not show their teratogenic potential [28-34]. (iv) The HCCSCA is appropriate for the evaluation of informative offspring but cannot provide data for other pregnancy outcomes, e.g. miscarriages in the study pregnancy.

\section{CONCLUSION}

A specific teratogenic risk of parenteral hCG treatments during the second and/or third gestational month of pregnancy was not found but the total (birth + fetal) prevalence of total CA group was somewhat higher in the offspring of mothers and it may be associated with the causes of previous miscarriages.

\section{ACKNOWLEDGEMENT}

Authors thank Erzsébet H. Puho, Ph.D. for her help in the statistical analysis of data.
ABBREVIATIONS
CA
$=$ Congenital abnormality
CI
$=$ Confidence interval
HCAR = Hungarian Congenital Abnormality Registry
HCCSCA = Hungarian Case-Control Surveillance of Congenital Abnormalities
hCG $=$ Human chorionic gonadotropin
OR $\quad=$ Odds ratio
SLE $\quad=$ Systemic lupus erythematosus

\section{REFERENCES}

[1] Conslson CJ. Molecular mechanism of drug action. Taylor \& Francis: London 1988.

[2] Rojas FJ. Ovulation induction. Effects of ovulation induction with gonadotrophins on the ovary and uterus and their implications for assisted reproduction. Hum Reprod 1995; 10: 2219-24.

[3] Czeizel AE, Dudás I, Gidai J, Horváth-Puhó E. No effect of human chorionic gonadotropin treatment due to threatened abortion in early pregnancy for birth outcomes. Cent Eur J Med 2007; 3: 71-6.

[4] Devaseelan P, Fogarty PP, Regan L. Human chorionic gonadotrophin for threatened miscarriage. Cochrane Database Syst Rev 2010; 12: CD007422.

[5] Czeizel AE, Rockenbauer M, Siffel CS, Varga E. Description and mission evaluation of the hungarian case-control surveillance of congenital abnormalities 1980-1996. Teratology 2001; 63: 176-85.

[6] Czeizel AE. The first 25 years of the Hungarian Congenital Abnormality Registry. Teratology, 1997; 55: 299-305.

[7] Czeizel AE, Intődy ZS, Modell B. What proportion of congenital abnormalities can be prevented? Br J Med 1993; 306: 499-503.

[8] Czeizel AE, Petik D, Vargha P. Validation studies of drug exposures in pregnant women. Pharmacoepidemiol Drug Saf 2003; 12: 409-16.

[9] Czeizel AE, Vargha P. Periconceptional folic acid/multivitamin supplementation and twin pregnancy. Am J Obstet Gynecol 2004; 191: 790-4.

[10] Ács N, Bánhidy F. Puhó HE, Czeizel AE. Maternal influenza during pregnancy and risk of congenital abnormalities. Birth Defects Res Part A 2005; 73: 989-96.

[11] Puho HE, Métneki J, Czeizel AE Maternal employment status and isolated orofacial clefts in Hungary. Cent Eur J Public Health 2004; 13: 144-8.

[12] Czeizel AE. Periconceptional folic acid and multivitamin supplementation for the prevention of neural tube defects and other congenital abnormalities. Birth Defects Res (Part A) 2009; 85: 260-8.

[13] Sakai N, Endo A. Potential teratogenicity of gonadotropin treatment for ovulation induction in the mouse offspring. Teratology 1987; 36: 229-33.

[14] Nishimura H, Shikata A. The maldevelopment of the fetuses of mice treated with gonadotropic hormone before the conception. Okajimas Folia Anat Jpn 1958; 31: 195-203.

[15] Hultquist GT, Engfeldt B. Growth of rat fetuses produced experimentally by means of administration of hormones to the mother during pregnancy. Acta Endocrinol (Kbh) 1949; 3: 365-76

[16] Bussi R, Ciamolillo C, Comoto L, Maraschin R, Komatsu S-U. Reproductive and developmental toxicity studies of SJ-0021 (rhFSH). Yakuri to Chiryo 1995; 23: 1953-97.

[17] Källen BAJ, Olausson PO. Maternal drug use in early pregnancy and infant cardiovascular defect. Reprod Toxicol 2003; 17: 255-61.

[18] Caspi E, Ronen J, Schreyer P, Goldberg MD. The outcome of pregnancy after gonadotrophin therapy. Br J Obstet Gynecol 1976; 83: 967-73.

[19] Ho HH, O'Connor JF, Nakajima ST, Tieu J, Overstreet JW, Lasley BL. Characterization of human chorionic gonadotropin in normal and abnormal pregnancies. Early Pregnancy 1997; 3: 213-4.

[20] Check JH, Liss JR, Katz Y, Shucoski K. Slow rising serial chorionic gonadotropins predict poor pregnancy outcome despite sonographic viability. Clin Obstet Gynecol 2003; 30: 193-4. 
[21] Scially AR. The reproductive toxicity of ovulation induction. Fertil Steril 1986; 45: 315-23.

[22] Bánhidy F, Lowry RB, Czeizel AE. Risk and benefit of drug use during pregnancy. Int J Med Sci 2005; 2: 100-6.

[23] Czeizel AE. The estimation of human teratogenic/fetotoxic risk of exposures to drugs on the basis of Hungarian experiences: a critical evaluation of clinical and epidemiological models of human teratology. Expert Opin Drug Saf 2009; 8: 283-303.

[24] Ben-Rafael Z, Dor J, Mashiach S, Blankstein J, Lunefeld B, Serr DM. Abortion rate in pregnancies following ovulation induced by human menopausal gonadotropin/human chorionic gonadotropin. Fertil Steril 1983; 39: 157-62.

[25] Zhang J, Olshan A, Cai W-W. Birth defects in relation to threatened abortion. Epidemiology 1994; 5: 341-4.

[26] Czeizel AE. Threatened abortion. In: Ács N, Bánhidy F, Czeizel $\mathrm{AE}$, Eds. Congenital abnormalities and preterm birth related to maternal illnesses during pregnancy. Springer: Dordrecht, Heidelberg, London, New York 2010; pp. 416-9.

[27] Czeizel AE, Rothman KI. Does relaxed reproductive selection explain the decline in male reproductive health? A new hypothesis. Epidemiology 2002; 13: 113-4.
[28] Czeizel AE, Huiskes N. A case-control study to evaluate the risk of congenital anomalies as a result of allylestrenol therapy during pregnancy. Clin Ther 1988; 10: 725-39.

[29] Bártfai Z, Kocsis J, Puho HE, Czeizel AE. A population-based case-control study of promethaine use during pregnancy. Reprod Toxicol 2008; 25: 276-85

[30] Petik D, Ács N, Bánhidy F, Czeizel AE. A study of the potential teratogenic effect of large doses of promethazine in 32 selfpoisoned pregnant women. Toxic Ind Health 2008; 24: 87-96.

[31] Czeizel AE, Rockenbauer M. The evaluation of drotaverine intake during pregnancy on fetal development. Prenat Neonat Med 1996; 1: 137-45.

[32] Czeizel AE, Erős E, Rockenbauer M, Sorensen HT, Olsen J. Shortterm oral diazepam treatment during pregnancy - a populationbased teratological case-control study. Clin Drug Invest 2003; 23 : 451-62.

[33] Gidai J, Ács N, Bánhidy F, Czeizel AE. No association found between use of very large doses of diazepam by 112 pregnant women for suicide attempt and congenital abnormalities in their offspring. Toxic Ind Health 2008; 24: 29-39.

[34] Shepard TH, and Lemire RJ, Catalog of Teratogenic Agents, 11th ed. Johns Hopkins Univ Press, Baltimore, 2004.

Received: September 07, 2010

Revised: May 15,2011

Accepted: May 26, 2011

(C) Dudás et al.; Licensee Bentham Open.

This is an open access article licensed under the terms of the Creative Commons Attribution Non-Commercial License (http://creativecommons.org/licenses/ by-nc/3.0/) which permits unrestricted, non-commercial use, distribution and reproduction in any medium, provided the work is properly cited. 